\title{
Construction Project Management Based on Building Information Modeling (BIM)
}

\author{
Yin Rui*, Lim Yaik-Wah, Tan Cher Siang \\ Faculty of Built Environment and Surveying, Universiti Teknologi Malaysia, Malaysia
}

Received July 26, 2021; Revised August 26, 2021; Accepted October 6, 2021

\section{Cite This Paper in the following Citation Styles}

(a): [1] Yin Rui, Lim Yaik-Wah, Tan Cher Siang, "Construction Project Management Based on Building Information Modeling (BIM)," Civil Engineering and Architecture, Vol. 9, No. 6, pp. 2055-2061, 2021. DOI: 10.13189/cea.2021.090633.

(b): Yin Rui, Lim Yaik-Wah, Tan Cher Siang (2021). Construction Project Management Based on Building Information Modeling (BIM). Civil Engineering and Architecture, 9(6), 2055-2061. DOI: 10.13189/cea.2021.090632.

Copyright $\bigcirc 2021$ by authors, all rights reserved. Authors agree that this article remains permanently open access under the terms of the Creative Commons Attribution License 4.0 International License

\begin{abstract}
In the construction industry, Building Information Modelling is primarily viewed as a catalyst for productivity and innovation. As projects have become more and more complex, there has been an increasing concern about the concept of project complexity. Understanding project complexity and managing contractors need to improve their management level as the rising building intricacy increases. In the construction industry, the contractors have faced many challenges, including workforce, increasing cost, inadequate risk management, unrealistic expectations/bad forecasting, limited skills, and delay problem. The project participants must coordinate and plan according to the project scope, including the construction process simulation, monitoring the construction quality, reducing rework, and improving economic benefits. Some of the main-contractor managements are trying to apply new modern technology. Building Information Modeling (BIM) is a tool used to the design, construction, and maintenance process of the whole cycle of the construction project. This article aims to analyze the BIM tool and take its advantage to improve the construction project management efficiency. The case study research approach is utilized to analyze the BIM tools. It includes the BIM $3 \mathrm{D} / 4 \mathrm{D} / 5 \mathrm{D}$ tools as the new method to build visualization model, execute clash detection, take-off quantity, simulate the construction process, make the work schedule graphically, and ensure the project is complete on time. This study is to research construction project management through applying the BIM tool. The BIM platform optimizes the design quality and improves construction work efficiencies, such as clash
\end{abstract}

detection, work schedule, quantity take-off, etc. The results are also helpful for the identification of research clusters and topics in the BIM community.

Keywords Construction, Project Management, Building Information Modeling

\section{Introduction}

Construction project management becomes more complex as the construction industry develops. There are differences in the project management results with different man-agreement methods [1]. In general, the construction project has many subcontractors to work together, such as piling, structure, architecture, Mechanical, and Electrical (M\&E), Landscape, and others. It is challenging to coordinate for each subcontractor. The lack of cooperation leads to reduce the work efficiency. The construction problems need more advanced technology to improve work accuracy and work efficiency [2].

BIM has emerged as a capability to transfer various construction information [3]. It contains the interaction of architecture, structure, mechanical, and electrical (M\&E), and construction information. This technology was developed from three-dimensional (BIM 3D) to construction time (BIM 4D), quantity survey (BIM 5D), and life-cycle management (BIM 6D). Some BIM applications were progressively used in the construction 
industry, such as structural analysis, construction simulation, cost management [4].

This article aims to analyze the BIM tool and take its advantage to improve the construction project management efficiency. It includes the BIM 3D/4D/5D tools as the new method to build visualization model, execute clash detection, take-off quantity, simulate the construction process, make the work schedule graphically, and ensure the project is complete on time.

\section{Materials and Methods}

\subsection{Description of Study Area}

The overall content of this study is to increase the understanding of BIM technology application in the different construction processes. The deeper objective is expected to contribute to construction project management. Series of literature reviews show some weakness in current project management practice [5]. This study involves $\mathrm{BIM} 3 \mathrm{D} / 4 \mathrm{D} / 5 \mathrm{D}$ recently performed in construction projects. The participants in construction activities include owner/developer, designer, contractor, and consultant.

Hatmoko et al. [6] surveyed the data from the stakeholders involved in the construction project through interviews and questionnaires methods. In this research, the researcher uses the case study approach to analyze the BIM tool. There is one case that the main contractor adopted the BIM tool to execute the project management. The application of BIM exactly meets the requirements of this research objective. The project is Forest City plot 26 project which is in Johor Bahru, Malaysia. The main contractor, Giant Leaf, used BIM technology to improve block $\mathrm{C} 2$ and $\mathrm{C} 4$ construction management. These are 40 stories of high-rise condominiums. The two precast buildings height is about 124.4 meters. The researcher analyzed the BIM application performance during this project management activities

\subsection{Data Collection}

The literature review method is comprehensively to recognize the research problems. It helps understand the history and current situation of construction project management also. Previous research on BIM applications was reviewed to meet the needs of this research. The data sources include books, journal articles, statistical data, internet information, and conference papers. Finally, the conclusion of BIM practice was deduced depends on the analysis. The critical steps were carried out to review the application of BIM. First is a comprehensive and extensive literature review to increase knowledge about data integration procedures during the pre-construction stage and in a construction project in traditional and
BIM-assisted projects. Second, this paper will investigate, discuss, and review the connection of BIM with the pre-construction phase of projects. For this purpose, specific keywords have been identified.

The main keywords that can reflect the essence of this review are "Building Information Modelling (BIM)", "data integration", "safety", "time"," budget", "cost", and "quality". After the identification of relevant keywords, the second step is searching for them in online databases of academic publications, such as "Science Direct", "Web of Science", "Google Scholar" and "Scopus." This extensive process of web search is initiated for collecting academic and applied publications related to the subject matter. While only concerned or relevant reviewing material like research thesis, conference papers, dissertations, research articles and journal papers are accepted and reviewed. Those papers and published research that included or argued selected keywords in Title/Abstract/Summary are then chosen for further study. Journal articles selected for conducting this research were peer-reviewed journals in concerned subjects.

Such as construction management, Safety Science, Renewable \& Sustainable Energy Reviews, Automation in construction, the Journal of Computing in Civil Engineering, Reliability Engineering \& System Safety and the International Journal of Project Management. Publications from standard committees like H.S.E., ISO and professional authorities, and conference papers are also considered. While in the final step, the information collected is critically analyzed, comparatively studied against current and potential obstacles to fill the gaps. Such methodology of research was also adopted for conducting numerous other studies as well.

The primary data collection is from the case study as the preliminary data. This method investigates the object characteristics and forming process by analyzing the project developer, consultant, and contractor. It is essential to work for summarizing relative materials. The primary data include BIM software types [7], the amount of clash detection, precast components installation simulation, take-off quantity, precast component modelling. This research's general conclusion and principle are inducted based on the BIM practice resource in this case study.

\section{Results}

\subsection{The BIM Application in Construction Management}

\subsubsection{The 3D BIM Application in Preconstruction Stage}

Digital technology provides new types of support for action decisions during construction activities. BIM application has previously identified how to inform engineering activities in the pre-construction stage [8]. As 
the development of the new method, BIM supports the project management better for building life cycle [9]. The main contract-tors make the scientific site plan before starting the construction work. Some of the project management teams optimize the site layout by BIM tool according to the actual situation.

The main works of the site plan include the in and out access, the different storage of material area, site office, the tower crane, the temporary water supply, and generator location. The construction site needs to keep machinery and material transportation traffic flowing. The principle of the site plan is to meet the construction activities requirements. In this case study, the BIM model displays the Tower Crane (T.C.) working area vividly. The TC-1 loading scope covers the purple room. The TC-2 loading scope covers the red zone, as Figure 1:

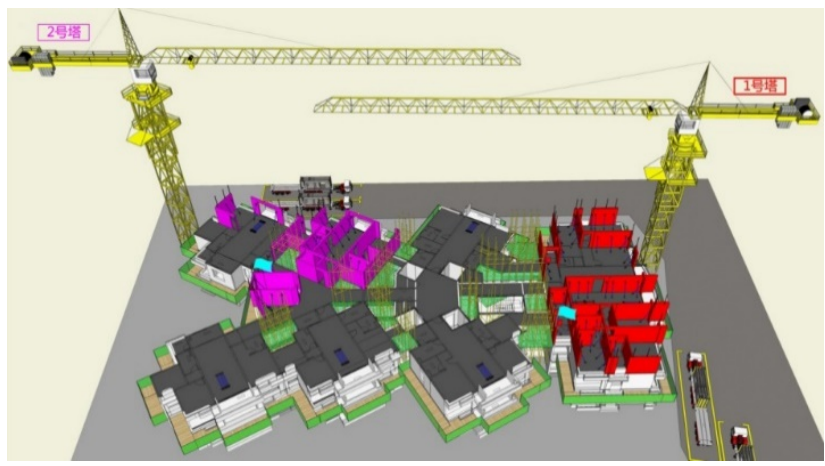

Figure 1. Example of BIM model for site layout

\subsubsection{The Clash Detection Work}

Clash detection is the critical phase and emerges in the shop drawing stage. Significantly, many sheets of steel are fighting in the exact location. In traditional construction project management, this type of hidden problem is hard to be checked during the pre-construction stage. As the application of BIM technology, this tool improves the clash detection work efficiency. The professional BIM model is integrated with construction information. The engineer takes advantage of the BIM model and solves the pipeline collision problem also. The clash inspection result could be exported in a short time. The clash detection problem can be positioned for the user. It considerably saves checking time if you use conventional 2D drawings. The BIM tool is convenient for designers to modify the pipeline immediately. This method improves the accuracy of design, reduces the generation of rework. It is conducive to the main contractor to strengthen the construction progress and quality management also. $[10,11]$ quickly verified the clash problems through the BIM tool. They modified the design of conflict points based on the BIM clash detection.

In the case study, the Forest City project blocks $\mathrm{C} 2$ and $\mathrm{C} 4$ have about 21,508 pcs precast components, as mentioned in Figure 2, 3. The main contractor, Giant Leaf company, adopted the BIM tool checking potential clash problems as following Figure 2, 3.

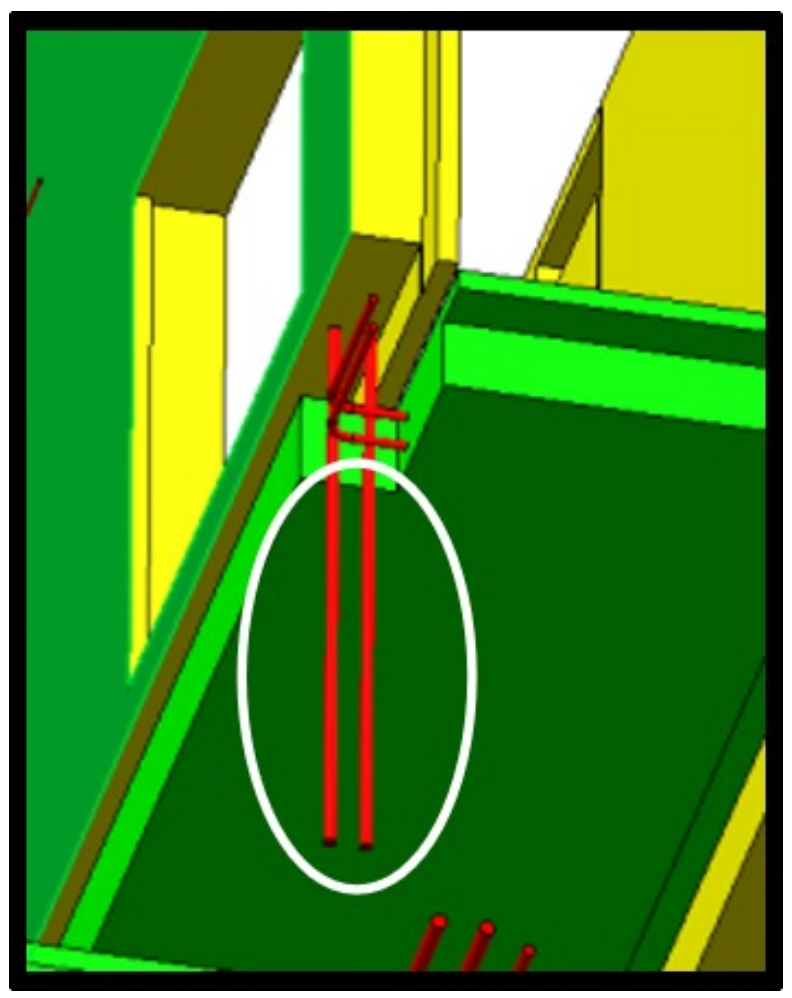

Figure 2. Example of BIM model for site layout

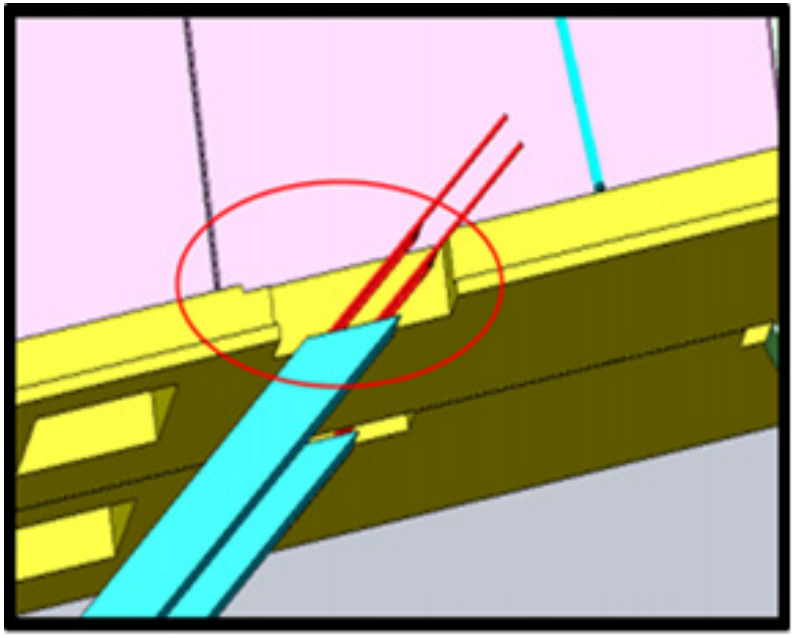

Figure 3. Example of BIM model for site layout

The designer applied BIM technology to carry out each precast component clash inspection before manufacturing [12]. This tool precisely locates the clash position. This project totals 154 clashes (Block C2: 82 nos+ Block C4: 72 nos). These are all steel fighting problems. The designer quickly modified the precast component shop drawing and avoided the same issues for 40 stories. But the designers have not checked the clashes between architectural and structural, Mechanical and Electrical. This method massively reduced defective precast component products also. 


\subsubsection{The Visualization of BIM Model}

The architects design the modern building with complex styles, such as arc-shaped, concave, bulge. It is hard to describe with a 2D drawing. For an experienced $\mathrm{CAD}$ designer to display more complex construction components, it needs east/south/west/north elevation, section, and other detail drawings. But one Revit 3D model can show all the above architecture information, such as drop, starting point, and endpoint of ramp slope, hidden drain, and the others. The construction engineers try to capture any section location drawing through the BIM tool [13]. It becomes an easy process to measure the construction dimension and level. The more significant benefit is to get construction information anytime, anywhere in comparison with conventional drawing.

During the design phase, the building drawing inevitably requires a lot of modification. The BIM provides the platform to support transformation quickly and coordinate relevant participants simultaneously [14]. In this case study, the precast building designer uses Revit software to design each precast component. For example, they made a 3D model to describe the balcony. The other participants get the accurate plant box location and size quickly. The total amount of BIM modelling as mentioned in Figure 4:

\begin{tabular}{|c|c|c|c|}
\hline \multicolumn{4}{|c|}{ Summary of Precast Component at Standard Level } \\
\hline $\begin{array}{c}\text { Block } \\
\text { No. }\end{array}$ & $\begin{array}{c}\text { Vertical } \\
\text { Components }\end{array}$ & $\begin{array}{c}\text { Horizontal } \\
\text { Components }\end{array}$ & $\begin{array}{c}\text { Max } \\
\text { Weight }\end{array}$ \\
\hline C5 & $157 \mathrm{PCS}$ & $115 \mathrm{PCS}$ & $7.23 \mathrm{~T}$ \\
\hline C6 & $107 \mathrm{PCS}$ & $81 \mathrm{PCS}$ & $6.80 \mathrm{~T}$ \\
\hline
\end{tabular}

Figure 4. The amount of BIM 3D model

\subsection{The 4D BIM Application in Construction Stage}

\subsubsection{The Simulation of Construction Process}

With the development of construction technology, the site work becomes more complex. The reasonable construction process and construction sequence are essential for the result of construction project management. Some of the leading contractors make simulations and analyses for the crucial construction process by BIM tool. The concept of BIM technology is to try it before doing it.

Gong et al. [15] showed that the 4D BIM tool supports a multi-party information-sharing platform beneficial to project management. This tool is helpful for the construction engineer to simulate some of the complex construction processes. Thus, they can get more accurate information during pre-construction. The site engineer and worker have a more intuitive understanding of the construction process. So, the engineers can modify and optimize their site work process or construction sequence. It becomes scientific guidance for executing construction site work in the pre-construction stage. Finally, the construction project management can improve the construction quality and working efficiency according to relative simulation and analysis as mentioned in Figures 5, 6.

The participants of construction activities have different working levels; some have poor ability to understand the complex construction process. So, the main contractor Giant Leaf company adopted the BIM technology to do the 3D visualization for technical training work. It improves the workers' more intuitive understanding of the construction process. The following two models display the staircase and four units precast component installation sequence.

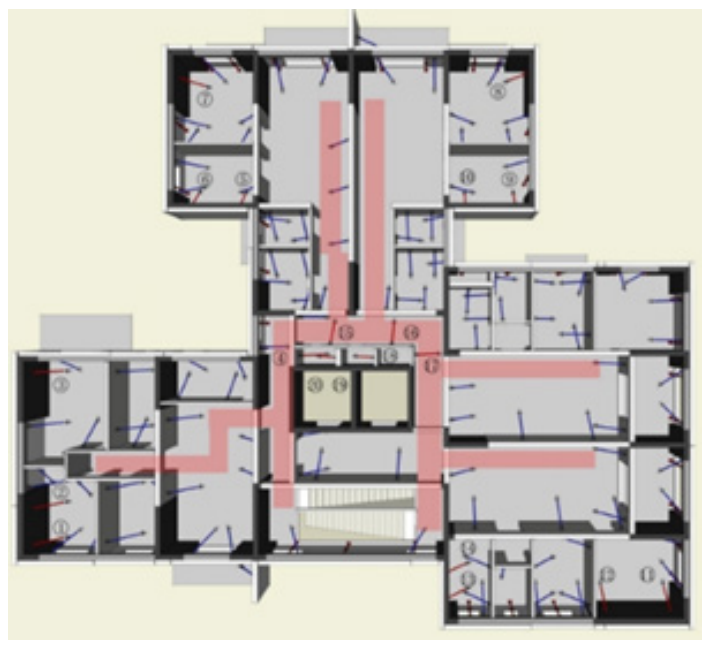

Figure 5. Example of BIM simulation for the installation process

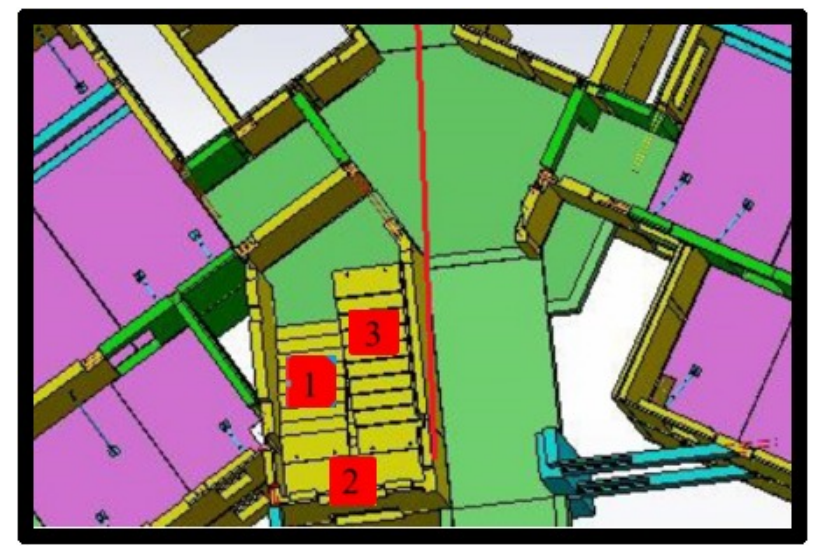

Figure 6. Example of BIM simulation for the installation process

\subsubsection{The Work Schedule Management}

The project work schedule is a crucial thing for project management. According to the contract items, the main goal is for the main contractor to complete the construction task in a limited time. Therefore, the project management should monitor the work progress. The main contractor often analyzes the work schedule deviation and makes effective measures to adjust the construction process. The new activities are to eliminate differences and ensure the whole project completion target. 
In general, the contractors use the Excel or Micro Project software to express the construction schedule. These tools are separated from the construction work process. This method is alone for construction project management. The depth of the software application is not satisfactory for some work schedule inspectors. The work schedule often changed due to actual construction process reasons. The inspectors need to take more time to verify the consistency between the work plan with the real situation.

The conventional tool planning level is lower for the construction schedule. Sometimes the rough plan leads to unreasonable or repetitive work on the construction site. So, the main contractor, Giant Leaf, tries to use BIM technology to make the dynamic work schedule according to the construction process. This method directly affects the construction project plan work. It brings convenience to monitor the construction work arrangement. This advanced management tool is helpful to control the project's progress [16]. It avoids some unnecessary works and shortens the construction work time. So, it improves work efficiency and increases economic benefits also.

\subsection{The 5D BIM Application in Quantity Survey}

\subsubsection{Take-off Quantity by BIM Model}

The conventional calculation tool needs more time to get the material quantity. Such as the Excel or Glodon software. Sometimes, the calculation amount is not accurate after the quantity surveyor wastes more time to count it. Furthermore, it is hard to check the amount between different quantity surveyors. So, the new quantity surveying method is exploited by the BIM tool. Many calculation processes are executed automatically by computer with the application of BIM technology [17].

The project designers use BIM technology to create the modelling with various construction information [18]. They categorize the different components, such as water pipes, doors, windows, columns, beams, slabs. It includes the material size, type, model, and other relative information. The designer can make numbering for each BIM model, then take off the quantity fast. The BIM 5D tool executes the counting process automatically. It does not need more time to verify the calculation result. The summary amount has mot dispute. It only needs to check the material types and specified areas.

Chan et al. [19] expressed 5D BIM as an innovation tool for project organizational effectiveness. It is easy for quantity surveyors (QS) to summarize relevant quantities quickly. This method helps the purchasing department make the order plan and control the correct material amount. It improves the work accuracy and works efficiently for the Q.S. department too.

\subsubsection{The Cost Management}

Vitiello et al. [20] implemented a simplified method based on the BIM model approach to evaluate the economic performance and economic losses. The quantity survey work is directed to impact project cost management. Some of the leading contractors use the BIM tool to control the project cost. They establish a lean operation management system according to the proper amount taken off by the BIM quantity calculation process.

Jalali et al. [21] represented a method to quantify total waste produced in the building life-cycle based on BIM technology. The proposed solution to reduce cost. In this case study, the main contractor Giant Leaf company verified the material amount between the actual site amount and quantity survey amount. They found out some of the actual materials are higher than the quantity from the BIM tool. The Q.S. and site engineer compared the result carefully. They found out some problems. Significantly, the site worker wasted more concrete material than the BIM calculation amount. Then, the project team analyzed why concrete debris was flowing: (1) The site ground level was uneven enough. It leads to more waste of $\mathrm{C} 10$ lean concrete. (2) The formwork of the ground beam was broken and led to cast C30 concrete again after repairing the formwork. (3) Several of the dimensions are more significant than the actual drawing size. It leads to more waste of concrete.

The Giant Leaf company's main contractor made the new management regulation and executed more training according to material quantity analysis. The new management method is as follows: (1) The quality inspector should strictly check the ground level before casting lean concrete. (2) The site engineer should strengthen the quality supporting timber for ground beam formwork. (3) The QC should inspect the accuracy of construction component size before casting concrete.

Therefore, the project team participants use the BIM 5D function to strengthen project cost management by controlling accurate material quantity.

\section{Finding and Discussion}

The prime aspect of this review is to investigate the role of BIM in construction projects and industry. As per the information collected by papers reviewed, the information or data needed and the application of visual modelling are the two aspects that need the most attention. People are aware of BIM intelligent 3D models, design plans, infrastructure planning, management assistance, and construction projects in pre-construction phases. Meanwhile, recent trends show that usage of drone technology may also appear in the equation for better depiction of trains and visual assistance. Still, the integration and comprehension of data are the most critical feat.

The review acknowledges the notion that optimal software BIM is not yet found. Kessler et al. also noticed 
the same idea, where BIM models lack geology, albeit a standard software is present in the market. That can be utilized for better access and visualization of geotechnical data. Nonetheless, these available softwares have their own advantages and disadvantages. All the software's lacks a particular function, such as bearing capacity, soil stratigraphy or strength parameters that are crucial to modelling. Nevertheless, if these shortcomings can be overcome, then it is indeed a revolutionizing technology.

\section{Conclusions}

The BIM technology expresses the comprehensive view of the building. It promotes Architecture, Engineering, and Construction (A.E.C.) development based on data integration [22]. The design result becomes more visualized if the designer adopts BIM technology. The BIM technology brings a visual model database that is evolved from the construction drawings. This is a significant difference with conventional 2D drawing, such as the AutoCAD tool. The 3D model can easily generate various elevation views, detail drawings, and section drawings. This method improves design work efficiency and reduces design errors.

[23] simulated a project and provided the existing risk management could be integrated into BIM for visualization. Therefore, many construction participants adopt BIM technology to create modelling with various information. The construction information was easily obtained from the model for the project management activities. It includes construction components' location, size, material type, work schedule, and others.

Based on the 3D model, the BIM 4D application adds time and the 5D application adds quantity factors. This technology integrates the cost information and project work schedule into the model. The project team executes the dynamic analysis by linking the actual site situation $[24,25]$. The clash detection process found many issues, and the visualization modelling becomes guidance for site plan work. Furthermore, the BIM 5D tool is helpful for a quantity surveyor to get proper material amounts quickly and improve cost management.

Through the application of BIM 3D/4D/5D tools, BIM technology provides various solutions for improving construction project management, including clash detection, contract management, quality management, cost control, and work schedule management

\section{REFERENCES}

[1] Y. Lu, P. Gong, Y. Tang, S. Sun, Q. Li. BIM-Integrated Construction Safety Risk Assessment at the Design Stage of Building Projects, Automation in Construction, Vol.124, 2021.
[2] T. A. Nguyen, P. T. Nguyen, S. T. Do, P. T. Phan. Application of Building Information Modelling (BIM) in Managing the Volume of High-Rise Building Walls, Materials Today: Proceedings, 2021.

[3] Sinaga, T., \& Husin, A. E. Analysis of Time Efficiency with CCPM Method and BIM in Construction Projects Construction of High-Rise Residential Building Basement. Civil Engineering and Architecture, Vol. 9, No. 5, pp. 1465 - 1477, 2021. DOI: 10.13189/cea.2021.090519.

[4] E. Kamel, A. M. Memari. Review of BIM's application in energy simulation: Tools, issues, and solutions, Automation in Construction. Vol.97, 164-180, 2018.

[5] M. Raj, N. K. Wadsamudrakar. Risk Management in Construction Project, International Journal of Engineering and Management Research. Vol.8, No.3, 162-167, 2019.

[6] J. U. D. Hatmoko, Y. Fundra, M.A. Wibowo, Zhabrinna. Investigating Building Information Modelling (BIM) Adoption in Indonesia Construction Industry, MATEC Web of Conferences, Vol. 258, 2019.

[7] D. Borna, M. Galić, U. Klanšek. A Survey on Integration of Optimization and Project Management Tools for Sustainable Construction Scheduling, Sustainability, Vol. 12, No. 8, 2020.

[8] J. A. Aranda, N. Martin-Dorta, F. Naya, J. Conesa-Pastor, M. Contero. Sustainability and Interoperability: An Economic Study on BIM Implementation by a Small Civil Engineering Firm, Sustainability, Vol. 12, No. 22, 2020.

[9] Y. Chen, J. Jupp. BIM and Through-Life Information Management: A Systems Engineering Perspective, Advances in Informatics and Computing in Civil and Construction Engineering, 137-146, 2018.

[10] L. Xiao, Y. Liu, Z. Du, Z. Yang, K. Xu. Model Analysis and Optimization of BIM Technology in High-rise Shear Wall Residential Structure, MATEC Web of Conferences. Vol. $267,2019$.

[11] G. Ma, J. Jia, J. Ding, S. Shang, S. Jiang. Interpretive Structural Model Based Factor Analysis of BIM Adoption in Chinese Construction Organizations, Sustainability Vol. 11, No. 7, 2019.

[12] Gangwar, G., Kaur, P., \& Singh, I. Principles of Design for Sustainable Group Housing Projects in India. Civil Engineering and Architecture, Vol. 8, No. 6, pp. 1234 1250, 2020. DOI: 10.13189/cea.2020.080608.

[13] Y. Qi, S. Chang, Y. Ji, K. Qi. BIM-Based Incremental Cost Analysis Method of Prefabricated Buildings in China, Sustainability, Vol. 10, No. 11, 2018.

[14] R. Zieliński, M. Wójtowicz. Different BIM levels during the design and construction stages on the example of public utility facilities, A.I.P. Conference Proceedings. Vol. 2078, 2018.

[15] P. Gong, N. Zeng, K. Ye, M. König. An Empirical Study on the Acceptance of 4D BIM in E.P.C. Projects in China, Sustainability, Vol.11, No.5, 1316, 2019.

[16] S. V. Tran, N. Khan, D. Lee, C. Park. A Hazard Identification Approach of Integrating 4D BIM and Accident Case Analysis of Spatial-Temporal Exposure, Sustainability Vol.13, No.4, 2021. 
[17] N. Sulaiman, S. K. Abid, U. Nazir, N. P. N. Mahmud, S. K. K. Abdul, H. F. M. Hafidz, A. F. Roslan, and N. A. Rahim. Need for Resilience Healthcare Facilities Management (RHFM) In Malaysia's Public Hospitals. A Critical Literature Review, Proceedings of the 2nd African International Conference on Industrial Engineering and Operations Management Harare, 2020.

[18] F. M. Amoruso, U. Dietrich, T. Schuetze. Development of a Building Information Modeling-Parametric Workflow Based Renovation Strategy for an Exemplary Apartment Building in Seoul, Korea, Sustainability, Vol.10, No.12, 2018.

[19] I.Y.S. Chan, A.M.M. Liu, B. Chen. Management Strategies for 5D-BIM Adoption in Hong Kong, Proceedings of the 21st International Symposium on Advancement of Construction Management and Real Estate, 1023-1039, 2018.

[20] U. Vitiello, V. Ciotta, A. Salzano, D. Asprone, G. Manfredi, E. Cosenza. BIM-based approach for the cost-optimization of seismic retrofit strategies on existing buildings. Automation in Construction. Vol.98, 90-101, 2019.
[21] F. Jalaei, M. Zoghi, A. Khoshand. Life cycle environmental impact assessment to manage and optimize construction waste using Building Information Modeling (BIM). International Journal of Construction Management. Vol.10, 317-328, 2018

[22] H. Wang, Y. Pan, X. Luo. Integration of BIM and G.I.S. in sustainable built environment: A review and bibliometric analysis, Automation in Construction, Vol.103, 41-52, 2019.

[23] Y. Zou, A. Kiviniemi, S. W. Jones, J. Walsh. Risk Information Management for Bridges by Integrating Risk Breakdown Structure into 3D/4D BIM, KSCE Journal of Civil Engineering, Vol.23, No.2, 467-480, 2018.

[24] S. K. Abid, N. Sulaiman, N. P. N. Mahmud, U. Nazir, N. A. Adnan, A Review on The Application of Remote Sensing and Geographic Information System in Flood Crisis Management, Journal of Critical Reviews, Vol. 7, No.16, 2020.

[25] E. N. Shaqour. The Role of Implementing BIM Applications in Enhancing Project Management Knowledge Areas in Egypt, Ain Shams Engineering Journal, 2021. 